\title{
Recurrent Appendix Mucinous Adenocarcinoma
}

National Cancer Institute

\section{Source}

National Cancer Institute. Recurrent Appendix Mucinous Adenocarcinoma. NCI

Thesaurus. Code C153579.

The reemergence of appendix mucinous adenocarcinoma after a period of remission. 